\title{
BMJ Open What happens when patients know more than their doctors? Experiences of health interactions after diabetes patient education: a qualitative patient-led study
}

\author{
Rosamund Snow, ${ }^{1}$ Charlotte Humphrey, ${ }^{2}$ Jane Sandall ${ }^{3}$
}

To cite: Snow R,

Humphrey C, Sandall J. What happens when patients know more than their doctors? Experiences of health interactions after diabetes patient education: a qualitative patient-led study. BMJ Open 2013;3:e003583.

doi:10.1136/bmjopen-2013003583

- Prepublication history for this paper is available online. To view these files please visit the journal online (http://dx.doi.org/10.1136/ bmjopen-2013-003583).

Received 11 July 2013 Revised 3 October 2013 Accepted 7 October 2013

\section{CrossMark}

${ }^{1}$ Patient Safety and Service Quality Research Centre, King's College London, London, UK

${ }^{2}$ Department of Health Care Evaluation, King's College London, London, UK ${ }^{3}$ Department of Social Science and Women's Health, King's College London, London, UK

Correspondence to Dr Rosamund Snow; rosamund.snow@kcl.ac.uk

\section{ABSTRACT}

Objective: To explore the impact of patient education on the lives of people with diabetes, including the effect on interactions with doctors and other healthcare professionals.

Design: Qualitative user-led study using longitudinal interviews and $146 \mathrm{~h}$ of participant observation. Data were analysed using a narrative approach.

Participants: 21 patients with type 1 diabetes, those either about to attend a patient education course or those who had completed the course in the previous 10 years.

Setting: Established patient education centres in three UK teaching hospitals teaching the Dose Adjustment for Normal Eating (DAFNE) course.

Results: Both postcourse and several years later, most participants spoke of the experience of taking part in education as life-changingly positive. It helped them understand how to gain control over a very complex disease and freed them from dependence on medical advice and restrictive regimes. However, interactions within the health system following patient education could be fraught. Participants emerged from the course with greater condition-specific knowledge than many of the healthcare professionals they encountered. When these professionals did not understand what their patients were trying to do and were uncomfortable trusting their expertise, there could be serious consequences for these patients' ability to continue effective self-management.

Conclusions: Patients who have in-depth knowledge of their condition encounter problems when their expertise is seen as inappropriate in standard healthcare interactions, and expertise taught to patients in one branch of medicine can be considered noncompliant by those who are not specialists in that field. Although patient education can give people confidence in their own self-management skills, it cannot solve the power imbalance that remains when a generalist healthcare professional, however well meaning, blocks access to medication and supplies needed to manage chronic diseases successfully. There is a role for those involved in primary and hospital care, including those supporting and training healthcare professionals, to recognise these problems and find ways to acknowledge and respect chronic patients' biomedical and practical expertise.

\section{Strengths and limitations of this study}

- Studies of patient education have been dominated by medical perspectives, resulting in an emphasis on questions about compliance and biomedical markers, with less attention paid to the impact on other parts of patients' lives. The strength of this study was its user-led focus, with a researcher from the diabetic community supported and advised by others from that community.

- The project fits the National Institute for Health Research INVOLVE definition of research for patient benefit: 'research 'with' or 'by' people who use services rather than 'to', 'about' or 'for' them.'

- This qualitative study allowed a rich in-depth exploration of a particular education intervention, but this approach has inherent limitations; we cannot assume some of the condition-specific details are necessarily representative of other populations and other conditions.

- However, the broader findings of the study are applicable across the board: it has offered a new insight into the potential difficulties faced by highly health-literate patients, and suggests a need for serious reflection on existing practices, power hierarchies and training paradigms within healthcare.

\section{INTRODUCTION}

For more than two decades the UK has been developing and refining effective patient education programmes in order to help those with long-term conditions to take responsibility for their own self-management and avoid unnecessary hospitalisation. ${ }^{1}{ }^{2}$ Diabetes care has a particularly strong track record, with over 70 regional courses in England alone, and national programmes now being adopted abroad, such as Dose Adjustment for Normal Eating (DAFNE) and Diabetes Education and Self-Management for Ongoing and Newly Diagnosed (DESMOND). ${ }^{3} 4$ Randomised controlled trials have shown improvements in specific 
health outcomes and condition-related quality-of-life measurements, and National Institute for Health and Care Excellence recommends that all people with diabetes should have access to this kind of structured education. ${ }^{5-7}$

For the patients themselves, however, these clinical outcomes are only one part of living with a chronic condition. Our study, the first entirely patient-led research undertaken in this field, explores several unaddressed areas: the role created for the patient during education, what it means to take part and consequences for patients' lives in the long term. This paper draws on that research, looking specifically at the experience of attending DAFNE and how it affects postcourse interactions with the health system.

\section{METHODS}

\section{Influence of service users}

Service users with type 1 diabetes were involved at every stage of the project, including choice of topic, formulation of research question, design, development and conducting of the investigation, as well as analysis and writing up. The James Lind Alliance (http://www. lindalliance.org/), INVOLVE (http://www.involve.org. uk/) and the entirely patient-led Diabetes.co.uk Forum (http://www.diabetes.co.uk) advised on the development of and recruitment to an Advisory Group for the study. The final membership comprised 15 people who, between them, had more than 400 years of living with diabetes, and experience of a variety of treatment regimes and patient education initiatives. Some had never attended patient education, some were DAFNE trained and some had experience of non-DAFNE programmes. The Advisory Group shared experiences to help inform the kinds of interview topics of relevance to patients with diabetes, gave feedback on patient information sheets, and three members participated in pilot interviews, on which they gave feedback. RS, herself a user-researcher with type 1 diabetes, had overall responsibility for the research design and implementation, including data collection, analysis and writing up.

\section{Design}

The study took an interpretive, qualitative approach. Those attending or teaching DAFNE courses acted as respondents or informants for the study, and a range of methods-interviewing, observations and course participation-were used. Semistructured interviews were conducted in order to allow these respondents' stories to emerge and give insight into the impact of the course on their overall lives, including their health-related interactions with others. Open-ended questions (such as 'tell me how you have learnt to manage diabetes') allowed interviewees to direct large parts of the interview to follow the narrative they wished to tell. ${ }^{8-11}$ If that initial narrative did not already include stories of interactions with others, they were prompted to think about times when they had to discuss diabetes with friends, family, work colleagues and healthcare professionals of all kinds. Post-DAFNE, participants were asked to reflect on their initial answers and consider how (and whether) they would fit DAFNE into the story of how they learnt to self-manage. They were also asked to consider any changes to the way they interacted with others about diabetes following the course.

The study aimed to look at changes in people's perceptions of their situation and their own and others' levels of expertise, so interviews with new DAFNE students before and after the course, observations and course documentation were included as part of the data making up the narratives in the study. ${ }^{12-14}$ This meant that changes connected with course attendance could be observed as they happened, and the immediate impact on participants' overall life narrative noted. Roughly half the participants fell into this 'new student' group. However, in order to explore how patients' narratives might change over a longer time-frame, the rest of the participants were recruited from DAFNE 'graduates' (those who had completed the course several years previously), who were asked for retrospective narratives in a single interview. Although the majority of interview data were collected in formal, recorded sessions with a topic guide, less formal discussion and exploration of ideas with students and educators also took place during observations.

\section{Participant selection and setting}

DAFNE centres are externally audited to ensure that students get the same quality of education wherever they attend the course. ${ }^{15}$ This consistency, along with DAFNE's national reach, was one of the reasons behind the choice of this programme for the research study over other patient education projects with more localised or internal variation. Several different study sites were included to increase the diversity of participants and venues, rather than specifically to compare and contrast different experiences from one DAFNE centre to another. Each site ran the course over five consecutive days, with specially trained teams of two healthcare professionals, a Diabetes Specialist Nurse and a dietitian, doing the teaching.

Participants were recruited from established DAFNE centres in three UK hospitals. All three were teaching hospitals with specialist Diabetes Clinics that continued to support patients along DAFNE principles postcourse. The study thus looked at the journey taken by a group of perhaps the country's most expert patients-those with one of the most complex conditions to manage, taught in one of the most comprehensive education programmes, administered by some of the most experienced programme leaders.

Patient education is open to everyone with established type 1 diabetes, and is recommended for all. ${ }^{6}$ For this study, potential participants for the 'new student' group were considered to be anyone accepted onto a DAFNE 
course at the chosen study sites during the study period (September 2011 to January 2012); 11 were interviewed. DAFNE graduates were recruited from course follow-up sessions $(n=4)$, ordinary clinic appointments $(n=4)$ and field contacts $(n=2)$, with the aim of recruiting a purposive sample, as heterogeneous as possible in terms of diagnosis era, stage of life at diagnosis, current age, educational level, type of work, ethnicity and gender. Participants in the 'graduate' group had taken part in DAFNE between 3 and 11 years previously, with a mean and median of 7 years since completing the course. Nobody who was approached to take part declined, although two people had to cancel the arranged interviews because of health or family problems and so were not in the end included in the study.

A breakdown of the participants' demographics can be found in table 1 .

In summary, longitudinal narrative interviews were conducted with 11 new students before their course; they were observed during education, and reinterviewed 3 months postcourse. Retrospective narratives were collected from 10 former students of DAFNE, and additional information gathered from seven teaching staff. In all, data were gathered from 32 interviews with patients and $146 \mathrm{~h}$ of observations, including 5 days of complete participation in DAFNE by a user-researcher with type 1 diabetes, RS.

\section{Analysis}

Transcripts and field notes were coded using NVivo V.9, using a mixture of thematic and structural narrative analysis. ${ }^{16} 17$ The ideal patient role and narrative being taught on DAFNE was compared with students' personal life stories, and with their stories of others' expectations of them once the course was over. The DAFNE curriculum document, patient-facing course booklet and field notes from observations and participant observation were analysed along with transcribed interviews and notes of classroom discussions. Following a thematic narrative approach, whole stories rather than fragments of data were coded by theme, using in vivo codes derived directly from the actual words used in observations or documentation. This allowed story themes, woven through several days or even across observations, to be collected and compared. For students' individual narratives, interview transcripts were used as one set of data; for the new student group, this was supplemented by sections in observations where they had told personal stories. Each participant was coded separately, and a précis document created for each to summarise the elements important to their story. This final version could then be compared, not only with each other but with the roles and themes taught on the DAFNE course (the DAFNE narrative). Participants' postcourse stories of diabetes-related interactions were examined to gain an insight into the metanarratives they were encountering and the cultural expectations with which they had to live; in other words, to discover the ways healthcare
Table 1 Demographics of participants

\begin{tabular}{|c|c|}
\hline \multicolumn{2}{|l|}{ Decade of diagnosis } \\
\hline Pre-1970 & 5 participants \\
\hline 1970 s & 3 participants \\
\hline $1980 s$ & 4 participants \\
\hline $1990 s$ & 2 participants \\
\hline Post-2000 & 7 participants \\
\hline \multicolumn{2}{|l|}{ Stage of life at diagnosis } \\
\hline Child & 8 participants \\
\hline Teenager & 2 participants \\
\hline Young adult (under 25) & 3 participants \\
\hline Adult (25 and over) & 8 participants \\
\hline \multicolumn{2}{|l|}{ Age at time of first interview } \\
\hline $20 s$ & 3 participants \\
\hline $30 s$ & 3 participants \\
\hline $40 s$ & 7 participants \\
\hline $50 s$ & 4 participants \\
\hline $60 s$ & 4 participants \\
\hline \multicolumn{2}{|l|}{ Employment situation } \\
\hline Full time (standard hours) & 10 participants \\
\hline Full time (shift work) & 2 participants \\
\hline Part time & 3 participants \\
\hline Student & 2 participants \\
\hline Unemployed/on sick leave & 2 participants \\
\hline Retired & 2 participants \\
\hline \multicolumn{2}{|c|}{ Last educational qualification taken } \\
\hline None & 2 participants \\
\hline GCSE or equivalent & 3 participants \\
\hline A level or equivalent & 8 participants \\
\hline Degree level or equivalent & 5 participants \\
\hline Postgraduate level & 3 participants \\
\hline \multicolumn{2}{|l|}{ Gender } \\
\hline Male & 9 participants \\
\hline Female & 12 participants \\
\hline \multicolumn{2}{|l|}{ Ethnicity } \\
\hline White British & 17 participants \\
\hline White other & 1 participant \\
\hline Black Caribbean & 3 participants \\
\hline
\end{tabular}

professionals and laypeople responded to graduates' status and knowledge in their new, post-DAFNE patient role.

\section{Reflexivity}

Of potential concern in this study is the issue of the reification of one user-researcher's experience at the expense of other people's stories. ${ }^{18}$ Several steps were taken to mitigate this potential problem. Although the project was designed and conducted by a single userresearcher, RS, the Advisory Group described above provided a wider range of perspectives on living with diabetes, acted as a sounding-board for ideas, and helped to develop, refine and pilot the interview schedule and topic guide. Practical help was also enlisted from others in order to mitigate issues associated with RS being the only investigator conducting interviews. JS and $\mathrm{CH}$ checked transcripts, advised with analysis and confirmed the extent to which respondents were allowed to tell 
their own stories. In addition, the opportunity to observe students on DAFNE and then conduct follow-up interviews meant that a rapport was built up over time, and it was possible to return to previous stories and statements for clarification or expansion if necessary.

Some researchers recommend the use of respondent validation or 'member checking', where participants are asked to comment on findings and the conclusions made from those findings, although the benefit of this as proof of a study's validity is contested. ${ }^{19}$ A limited form of this practice was used in this study. Although there was no formal process for gathering feedback on the findings from every participant, general concepts and emerging theories were discussed postinterview with those participants who expressed interest in the turns the study was taking, and the insights gained in these discussions were invaluable.

\section{RESULTS}

\section{Expectations: the role of the expert patient}

Consistently across all observed courses, students were encouraged by tutors to adopt certain ideals. Among these were concepts of empowerment, expertise and independence. These principles are keystones of much patient education in the last couple of decades. ${ }^{120}$ As can be seen in the extract below, when students made statements suggesting blind compliance or dependence on doctors, they were gently challenged to think of themselves differently; as an empowered and expert patient, no longer dependent on doctors for decisions, but able to talk about their treatment requirements with healthcare professionals as an equal:

Student: 'My consultant told me to [take insulin at a certain time].'

Tutor: 'You'll all be DAFNE trained by the end of the week, you will be having a discussion with your doctors about your insulins!'

\section{Observation field notes}

The structure and complexity of DAFNE course content has been written about in depth elsewhere, including the benefits for patients in terms of blood glucose control; but the amount of knowledge imparted, and the quantity of self-management work, is not always emphasised. ${ }^{5}{ }^{21}$ Students in this study were expected to learn how to take control of their own treatment regime at a very high level, interpreting complex patterns of blood glucose results over time in order to make constant alterations to insulin dose and timing. This included understanding not only how to count carbohydrates, but also the action and interaction of different kinds of insulin, the interaction of foods to create an overall glycaemic index of a meal, the impact of hormones, stress, alcohol, different kinds of exercise, travelling across time zones, managing pregnancy and breast-feeding, and how to self-manage specific problems such as dawn phenomenon, rising blood glucose during various severities of illness and hypoglycaemia unawareness.

In the DAFNE narrative, the patient is not a passive victim of circumstance. In the following extract, a student's summary of previous experience as an inpatient is listened to, then a more active, independent role is suggested for the future:

Student: 'Whenever I've gone to hospital, because I'm diabetic, they put me on a drip, everything.'

Tutor replies that the Sick Day Rules [specific selfmanagement guidelines] are there 'to help you avoid that situation'.

Observation field notes

In summary, the DAFNE graduate is taught not only key information, but also to accept a new role for him or herself in the health system and the wider world: as empowered, knowledgeable and independent.

\section{Experience-taking on the new role}

Participating in the kind of detailed, comprehensive selfmanagement education offered by DAFNE had a very positive impact on the personal lives of nearly everyone in the study. Participants from all groups talked of 'lifechanging' experiences on the course, and of having been freed from the 'shackles' of a confusing or restrictive treatment regime by being given 'the tools of the trade' to manage a central aspect of their own lives.

I mean I really have nothing but praise for [DAFNE], it has been properly transformative in ... in a fundamental way, I've got a fundamentally better understanding of what it is that's actually wrong with me. Um... and that, yeah, that just allows me to be a lot freer.

\section{Harry, new student, speaking in post-DAFNE interview}

Those who had already built up self-management expertise precourse talked about 'fine-tuning' or solving a specific problem that had been causing them difficulty; nobody was entirely negative about attending DAFNE.

In short, students were largely comfortable with the new patient role being offered them via DAFNE. Knowledge, and independence from doctors and restrictive regimes, were mostly valued, although support from DAFNE specialists postcourse was very much appreciated by some. The relationship of students to 'empowerment' was slightly less clear cut; although power and control over diabetes was hugely enhanced by DAFNE, empowerment within the health system was more problematic, as we describe below. 


\section{Consequences: a clash of roles}

Postcourse, participants were often cast into ambiguous roles in healthcare interactions. Both the new student and the graduate groups had similar experiences; frequently, the condition-specific biomedical and practical information they had learnt was far greater than that of their doctors or nurses.

This was not necessarily a problem for everyone. Jane, below, described a positive experience with a primary care doctor who was keen to learn more and trusted her expertise:

I had an insect, I had a mozzie bite that closed my eye, bit me on the eye just here, the soft bit above the eye. And my eye swelled up, and I went to a walk-in clinic. And they wanted to give me steroids, which obviously push your blood sugar up, and I said 'well I know that's going to happen, I can manage my blood sugar if it does shoot up, I can increase my insulin and I use the DAFNE, do you have DAFNE?' and I had to go step by step through with [this doctor] how it worked. And he wrote loads of notes; it was really interesting, he wrote loads and loads of notes.

\section{Jane, DAFNE graduate, talking six years post-course}

Some participants simply avoided less specialist healthcare professionals if they could, relying instead on advice from their DAFNE tutors. However, this was not always possible, and in many health interactions, patients and healthcare professionals struggled to manage the tensions that arose from the partial role-reversal of expertise after selfmanagement education. In some cases basic or even inaccurate information was imposed on patients, who on the whole swallowed their annoyance in silence:

I went to a nurse [...] for like, I can't remember what even for, a flu jab or something, um ... and, um [...] she started giving me advice about my blood sugars and it really, it really got on my nerves, because they were just completely, completely counter to everything that I'd just been taught. And, and obviously not right?

Interviewer: What did you say?

I, I didn't, I didn't say anything. I just left it.

Interviewer: So she didn't know that you... what you were thinking?

No. There's no point getting into an argument.

\section{James, new student, speaking in post-DAFNE interview}

Where this tension became more serious was in situations where a less knowledgeable doctor had considerable power over the expert patient. This was most often seen in interactions with general practitioners (GPs), who restricted prescriptions, sometimes surreptitiously, when they did not understand the importance of blood testing to the patient's self-management regime. Using DAFNE principles, students learn how to achieve tighter, smoother blood glucose control by performing blood tests at least four times a day, using the results to make decisions about insulin dosage as well as ensuring that dangerously high or low blood sugars could be avoided. For some, this meant a considerable increase in test strip requirements as they took on the extra work to improve blood glucose control. Although course tutors provided letters for GPs explaining the necessity for these adjustments, interviewees reported having to be 'quite tough' to successfully negotiate with primary care teams who were reluctant to absorb the rise in short-term costs. Even when changes had apparently been agreed, they were sometimes reversed by healthcare staff without explanation or warning.

Julia's story, below, is an example of the kind of interaction that could arise in these circumstances. Although her GP did not refuse the prescription request outright, the dispensary simply reduced the amount asked for without explanation:

'So I went to pick up my prescription, I'd asked for four boxes, so I went to pick up my prescription when they were ready to go and pick it up, my husband got it and there were only two.

So I rang them up. I said: 'There are only two boxes.'

'- That's all you need.'

So I said: 'Oh right. Why's that?'

So she said, um: 'Well you only do two tests a day, and that will last you for months.'

\section{$[.$.}

So I said: 'So, as you can see on the letter from the diabetes specialist tutors\} they're asking for me to have adequate supplies to do x number of blood tests a week.'

'- Well I think it's quite ridiculous, you don't need that many.'

Julia, diabetic 50 years, new student speaking post-DAFNE.

Phil, mentioned earlier, was another typical example. He recontacted RS 6 months after data collection ended, with an update: his GP, who had originally agreed to prescribe blood test strips, had subsequently taken the strips off repeat prescription and insisted on Phil taking time off work every month to come into the surgery and justify the next month's supply. Since this was not always possible to do, he had to reduce his testing and his blood glucose had begun to rise again. As Phil put it, his doctor did not 'win the battle' because of superior medical knowledge; the GP simply had more power, and chose to exercise it. 
Healthcare professionals who were reluctant to trust patients' expertise in daily management could also cause difficulties. For example, one participant told of being sent to hospital when her blood glucose happened to be high because of an infection (something she had been taught to self-manage at home using DAFNE principles):

I don't go to my GP for anything to do with my diabetes, because they mainly deal with Type 2 diabetics. [...My GP] sent me to hospital when I had my blood sugar... I went in to see him about something and my blood sugar was 18 , which was not unusual. And he called an ambulance and I said to him he was being O.T.T., because not many Type 2 diabetics would go to A\&E.

\section{Interviewer: Did he listen or did he still call the ambulance?}

He listened, but he still called the ambulance.

Interviewer: And then what happened?

Well I was in hospital for two days! [...] And then I had trouble getting out of hospital, because I didn't meet the criteria and I'm saying to them 'please, just let me go home, this is unnatural, you know, I'm stuck in bed, my blood sugars aren't coming down because I'm stressed, I've got an infection, it's no good putting me on...' you know, because I was on a sliding scale, I said 'you don't understand, you don't understand, you don't understand...'

\section{Mary, DAFNE graduate, talking nine years post-course}

Although the GP and hospital staff meant well, they had failed to appreciate not just the emotional but also the physical impact on the patient of their actions. Mary gave her account with great emphasis. She described her unnecessary hospitalisation and subsequent events as 'frightening' because of the lack of power she was allowed over her own body; she could only watch her blood sugar rise needlessly without being able to use her own skills and expertise to keep herself safe. During the experience of being put on a 'sliding scale' (intravenous insulin and glucose administered in hospital), the patient completely loses control over his or her diabetes, surrendering management to hospital staff who are unlikely to be diabetes specialists. The National Diabetes Inpatient Audit has shown that in more than a third of cases this results in medication errors, which can lead to coma and occasionally death. ${ }^{22}$

\section{DISCUSSION}

\section{Principal findings}

People graduating from intensive patient education courses such as DAFNE emerge with disease-specific biomedical, experiential and practical knowledge that exceeds that of many healthcare professionals. From the stories told by participants in this study, it was clear that serious obstacles to self-management arose when generalist and even specialist doctors and nurses were not comfortable with patients who had a high level of expertise. While this has been noted elsewhere in more general terms, ${ }^{23}{ }^{24}$ this is the first study to confirm these findings in terms of healthcare professionals' reactions to formally trained Expert Patients. Although some healthcare teams were happy to support course graduates and even learn from them, this attitude could not be counted on, particularly when patients made budgetary demands that the budget-holders did not fully understand, such as requests for home blood testing equipment. Expertise taught to patients in one branch of medicine can be considered non-compliant by those who are not specialists in that field, and in some circumstances, such as inpatient care, self-management may be greatly discouraged or even forbidden by hospital policy.

Patient education has the potential to change people's lives for the better in a way that is perhaps not fully captured by standard clinical and quality of life outcome assessments. As well as offering practical information, DAFNE teaches people with diabetes to consider a new role as expert, independent and empowered patients. Participants in this study found that hugely helpful, not only in terms of biomedical improvements, but also in terms of taking control over their own lives with chronic disease. However, there is evidence that having learnt how to self-manage successfully, patients find it frustrating, at best, and frightening, at worst, to have access to self-management resources denied them; in some cases problems with postcourse interactions may be hindering patients' ability to hit biomedical targets and stay healthy.

\section{Strengths and limitations}

Traditionally, studies of patient education have been dominated by medical perspectives, with very little formal research conducted by patients themselves. This has resulted in emphasis on questions about compliance and biomedical markers, with less attention paid to the impact of educational interventions on other parts of patients' lives. The strength of this study was its user-led focus, with a researcher from the diabetic community supported and advised by others from that community. The project fits wholly within the National Institute for Health Research and INVOLVE definition of research for patient benefit: 'research 'with' or 'by' people who use services rather than 'to', 'about' or 'for' them. ${ }^{, 25}$

The choice of a narrative methodology and semistructured topic guide allowed patients to choose what to emphasise in the stories they told about themselves, but this approach had its inherent limitations too, as did the decision to restrict the research to a single chronic illness and just one patient education course. The small sample size allowed in-depth qualitative analysis to take place, but both sample size and the particular challenges involved in managing type 1 diabetes mean that we cannot assume disease-specific findings 
are representative of other populations and other conditions. However, the broader findings of the study are applicable across the board: it has offered a new insight into the potential difficulties faced by newly educated patients, and suggests a need for serious reflection on existing practices, power hierarchies and training paradigms within healthcare. There may be local differences in different populations, but the paradox remains: patients are being given expertise and confidence to self-manage, but there remains no pathway to having these skills recognised or valued more generally by those with power and access to resources. At best, this leaves patients vulnerable; at worst, it can undermine their hard work and health status.

Studies of posteducation health interactions have been rather limited to date. Some evaluations have hinted at potential conflicts between knowledgeable patients and less knowledgeable health professionals, and the potential for this conflict to erode health outcomes over time, ${ }^{5} 26$ but this has rarely been a focus of research. Previous qualitative work in diabetes education has identified the importance of ongoing support from healthcare professionals in patients' ability to self-manage along the lines taught on the course. ${ }^{27-29}$ However, these studies focus on the relationship between the specialist and patient rather than interactions with generalist healthcare professionals. In our study we found specific problems with interactions in primary and hospital care. This suggests that the power held by GP prescribers should not be overlooked when considering patients' ability to self-manage successfully.

\section{Implications and future research}

Although patient education is recommended for those with chronic conditions in general, ${ }^{130}$ the implications for the education of healthcare professionals are not currently considered in parallel. While modern medical and nursing education focuses on patient-centred care, ${ }^{31} 32$ it does not prepare healthcare students for situations in which their patients have more biomedical and practical knowledge than they do about a specific treatment regime or illness. ${ }^{33}$ When the role of the patient in a healthcare interaction is ambiguous and contested, problems arise on both sides, and extra work is required by both patient and professional. Although courses like DAFNE could include sessions preparing students for postcourse interactions, there are limits to the extent to which patient education can mitigate these problems. In the districts where this study took place, work was already being carried out to help support DAFNE graduates who needed to go into hospital, and to ensure they got letters to enhance their authority when asking for supplies from primary care. Findings from this study would suggest that this work is very much needed. However, even when this support was in place, graduates continued to encounter disempowering practices from healthcare staff who were not DAFNE-aware. When healthcare practitioners do not understand the patient's self-management requirements or trust their ability, they may put up obstacles to improved health outcomes by limiting medical supplies or insisting on unnecessary hospitalisation. As more chronic illness care is put into the hands of generalists, such situations are likely to arise more and more often; the importance of teaching strategies to cope with patient expertise, rather than see it as a threat, is of increasing relevance.

Although this study has provided an insight into the kinds of issues encountered by people after formal education, further research with both patients and healthcare professionals is needed to establish how widespread these problems are on a national level, and whether similar issues are faced by patients with other kinds of chronic conditions following other styles of Expert Patient Programme.

\section{CONCLUSIONS}

Healthcare professionals cannot become experts in the detailed management of every complex condition; gathering specialist input from others has long been an important part of treatment decision-making. Doctors, nurses and others whose attitudes impact on patient care must be supported to extend that model of shared expertise to work with those who have chronic illnesses, seeing the patient as part of the healthcare team, and the patient's condition-specific biomedical knowledge as a valuable resource, not a threat.

Acknowledgements This article presents independent research commissioned by the National Institute for Health Research (NIHR).

Contributors RS designed and carried out the research, and drafted the paper. She is the guarantor. JS and CH supervised research, reviewed and edited the paper.

Funding RS has a Patient Safety and Service Quality Fellowship award from the National Institute for Health Research (NIHR).

\section{Competing interests None.}

Ethics approval This study was supported by a National Institute for Health Research grant, awarded to RS as an independent researcher. Ethics approval was obtained from the NHS NRES Committee (REC reference 11/L0/0819) and from the relevant Research and Development Departments from the hospital NHS Trusts before the study began. All identifying details of participants have been removed and all names are pseudonyms.

Provenance and peer review Not commissioned; externally peer reviewed.

Data sharing statement The presented data are anonymised and risk of identification is low. Extra data are available by emailing RS.

Open Access This is an Open Access article distributed in accordance with the Creative Commons Attribution Non Commercial (CC BY-NC 3.0) license, which permits others to distribute, remix, adapt, build upon this work noncommercially, and license their derivative works on different terms, provided the original work is properly cited and the use is non-commercial. See: http:// creativecommons.org/licenses/by-nc/3.0/

\section{REFERENCES}

1. DoH. The expert patient: a new approach to chronic disease management for the 21st century. London: Department of Health 2001.

2. DoH. The National Service Framework for long term conditions. London: Department of Health, 2005.

3. DEN Steering Group. The Diabetes Education Network-Home. Diabetes Education Network, 2013 
4. DAFNE Collaborative. DAFNE vital statistics. National DAFNE Office, 2011.

5. DAFNE Study Group. Training in flexible, intensive insulin management to enable dietary freedom in people with type 1 diabetes: dose adjustment for normal eating (DAFNE) randomised controlled trial. BMJ 2002;325:746-9.

6. NICE. Diabetes in adults quality standard. London: National Institute for Health and Clinical Excellence, 2011.

7. Davies MJ, Heller S, Skinner T, et al. Effectiveness of the diabetes education and self management for ongoing and newly diagnosed (DESMOND) programme for people with newly diagnosed type 2 diabetes: cluster randomised controlled trial. BMJ 2008;336:491-5.

8. Holloway W, Jefferson T. Doing qualitative research differently. Sage, 2000.

9. Mishler EG. Research interviewing: context and narrative. Harvard University Press, 1991.

10. Kvale S. InterViews. London: Sage, 1996

11. Riessman C. Narrative analysis. London: Sage, 1993.

12. Miller T. Losing the plot: narrative construction and longitudinal childbirth research. Qual Health Res 2000;10:309.

13. Bryman A. Social research methods. Oxford: Oxford University Press, 2004.

14. Thomas C. Negotiating the contested terrain of narrative methods in illness contexts. Soc Health IIIn 2010;32:647-60.

15. Oliver L, Thompson G. The DAFNE collaborative: experiences of developing a nationally delivered evidence-based, quality-assured programme for people with type 1 diabetes. Pract Diab Int 2009;26:371-7.

16. Riessman CK. Narrative methods for the human sciences. London: Sage, 2008

17. Somers MR. The narrative constitution of identity: a relational and network approach. Theory Soc 1994;23:605-49.

18. Beresford $P$. User involvement in research and evaluation: liberation or regulation? Soc Policy Soc 2002;1:95-106.

19. Murphy E, Dingwall R. Qualitative methods and health policy research. Aldine de Gruyter, 2003.

20. Abraham C, Gardner B. What psychological and behaviour changes are initiated by 'expert patient' training and what training techniques are most helpful? Psychol Health 2009;24:1153-65.
21. Lawton J, Rankin D. How do structured education programmes work? An ethnographic investigation of the dose adjustment for normal eating (DAFNE) programme for type 1 diabetes patients in the UK. Soc Sci Med 2010;71:486-93.

22. NHS. National Diabetes Inpatient Audit (2010) Summary Findings from the National Diabetes Inpatient Audit (NaDIA) 2010 (England). NHS Diabetes, 2010.

23. Paterson B. Myth of empowerment in chronic disease. J Adv Nurs 2001;34:574-81.

24. Thorne SE, Ternulf Nyhlin K, Paterson BL. Attitudes toward patient expertise in chronic illness. Int $J$ Nurs Stud 2000;37:303-11.

25. NIHR. PPI-information for researchers. Leeds: National Institute for Health Research, 2012

26. Rankin D, Heller S, Lawton J. Understanding information and education gaps among people with type 1 diabetes: a qualitative investigation. Patient Educ Couns 2011;83:87-91.

27. Casey D, Murphy K, Lawton J, et al. A longitudinal qualitative study examining the factors impacting on the ability of persons with T1DM to assimilate the Dose Adjustment For Normal Eating (DAFNE) principles into daily living and how these factors change over time. BMC Public Health 2011;11:672.

28. Murphy K, Casey D, Dinneen S, et al. Participants' perceptions of the factors that influence Diabetes Self Management Following a Structured Education (DAFNE) programme. J Clin Nursing 2011;20:1282-92.

29. Rankin D, Cooke DD, Elliott J, et al. Supporting self-management after attending a structured education programme: a qualitative longitudinal investigation of type 1 diabetes patients' experiences and views. BMC Public Health 2012;12:652.

30. DoH. Six years on: delivering the Diabetes National Service Framework. London: Department of Health, 2010.

31. Bodenheimer T. Patient self-management of chronic disease in primary care. JAMA 2002;288:2469-75.

32. Stewart M. Patient-centered medicine: transforming the clinical method. Radcliffe Publishing, 2003.

33. Spencer J, Blackmore D, Heard S, et al. Patient-oriented learning: a review of the role of the patient in the education of medical students. Med Educ 2000;34:851-7. 